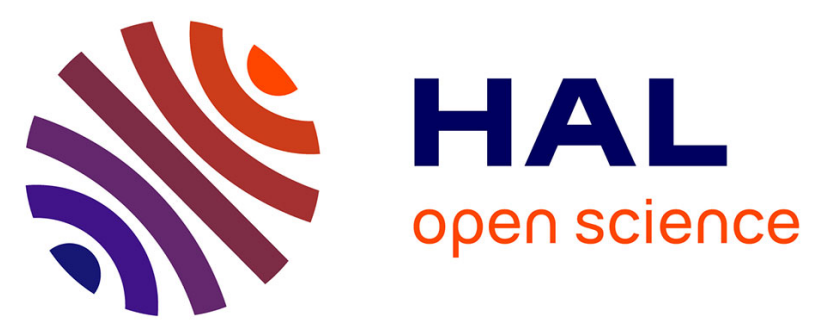

\title{
Linguistic intergroup bias at school: an exploratory study of black and white children in France and their implicit attitude towards another
}

Edith Salès-Wuillemin, Laurence Masse, Isabel Urdapilleta, Wendy Pullin, Corinna Kohler, Sabine Guéraud

\section{To cite this version:}

Edith Salès-Wuillemin, Laurence Masse, Isabel Urdapilleta, Wendy Pullin, Corinna Kohler, et al.. Linguistic intergroup bias at school: an exploratory study of black and white children in France and their implicit attitude towards another. International Journal of Intercultural Relations, 2014, 42, pp.93 - 103. 10.1016/j.ijintrel.2014.06.002 . halshs-01822271

\section{HAL Id: halshs-01822271 \\ https://shs.hal.science/halshs-01822271}

Submitted on 17 Feb 2019

HAL is a multi-disciplinary open access archive for the deposit and dissemination of scientific research documents, whether they are published or not. The documents may come from teaching and research institutions in France or abroad, or from public or private research centers.
L'archive ouverte pluridisciplinaire HAL, est destinée au dépôt et à la diffusion de documents scientifiques de niveau recherche, publiés ou non, émanant des établissements d'enseignement et de recherche français ou étrangers, des laboratoires publics ou privés. 
Running Head: LINGUISTIC INTERGROUP BIAS AT SCHOOL

LINGUISTIC INTERGROUP BIAS AT SCHOOL: AN EXPLORATORY STUDY

OF BLACK AND WHITE CHILDREN IN FRANCE AND THEIR PERCEPTIONS

OF ONE ANOTHER

Salès-Wuillemin, $E^{I}$., Masse, L., Urdapilleta, I., Pullin, W., Kohler, C., Gueraud, S.

(1) Corresponding Author : University of Burgundy, Laboratory Psy-DREPI

(Psychology, Interpersonal Dynamics and Identity Processes)

Edith.Sales-Wuillemin@u-bourgogne.fr

Rerence : Salès-Wuillemin, E ., Masse, L., Urdapilleta, I., Pullin, W., Kohler, C., Gueraud, S. (2014). Linguistic intergroup bias at school : an exploratory study of black and white children in France and their implicit attitude towards another, International Journal of Intercultural Relations, 42, 93-103. DOI : 


\begin{abstract}
“Linguistic Intergroup Bias” (LIB) (Maass, Castelli, \& Arcuri, 2000) was investigated in French elementary schools between children of the French majority group (White children of European heritage) and a French minority group (Black children from SubSaharan Africa). Participants $(\mathrm{N}=360 ; 7-11$ year-olds; mean age $=10.36, S D=.85)$ were shown photographs presenting a target character (ingroup or outgroup) engaging in a positive behavior (e.g., a helping action) or a negative behavior (e.g., an aggressive action). Demonstrations of ingroup favoritism with no outgroup derogation were expected for White children from the majority group. These hypotheses were confirmed. Unexpectedly, the same pattern of results was found for the minority group: ingroup favoritism and no outgroup derogation. Theoretical and applied implications of these findings are discussed.
\end{abstract}

Keywords: linguistic intergroup bias, ingroup favoritism, outgroup derogation, majority/minority group 
Linguistic Intergroup Bias at School: An Exploratory Study of Black and White Children in France and their Perceptions of One Another

Studies on intergroup relations vary widely concerning findings on ingroup and outgroup biases: ingroup favoritism and outgroup derogation. Among these studies, some have examined the effects of group status (majority $v s$ minority). Intercultural relations in France are a subject of central concern because it is a country that has experienced a continuous influx of immigrants, with a significant contingent from African countries (e.g., Mali, Senegal, Mauritania, etc.).

According to the INSEE (French National Institute of Statistics and Economic Studies), France had 5.5 million immigrants in 2010 of which $42.8 \%$ came from Africa (13\% from Sub-Saharan Africa), $33 \%$ from Europe, and 14.3\% from Asia. Thus, although France has a high percentage of immigrants from a diversity of ethnic origins, immigrants suffer inequalities in employment, housing, and access to health care. In terms of employment, a survey of City of Paris civil servants by Eberhard and Simon (2012) published by the French National Institute of Demographic Studies (INED) showed that $70 \%$ of the immigrants were relegated to jobs not requiring particular skills or education, $60 \%$ of them were overqualified for these jobs, and $77 \%$ of them admitted to experiencing discrimination.

In contrast to North Americans, French social psychologists have conducted few studies on "Black" and "White" intergroup relations despite the existing context of discrimination. In fact, to the best of our knowledge, there are no social psychological studies that include participants of the Black minority. 
Yet it is difficult to adapt results from North-American studies to a European perspective :

Similarities between Europe and North America are more superficial than their actual deep differences. Focusing on European ethnic research not only means an extension from one cultural context to another but also taps vastly different historical backgrounds that shape even current debates on interethnic relations. Europe has had a longer and deeper history of colonization than the United States. In turn, the United States had slavery - an institution unknown in Europe as a mass phenomenon since the Middle Ages. Additionally, Europe never had a comparable civil rights movement primarily driven by ethnic minorities as the United States did in the 1960s (Zick, Pettigrew \& Wagner, 2008, p. 234).

Thus, the aim of the present study was to explore the relations between White (majority group) and Black (minority group) school children in France. In order to pick up implicit attitudes and to avoid social desirability biases, we used a linguistic measure.

We focused on a school context because a school is a mirror of a society (Snyders, 1976): each school and each classroom reproduce inequalities of the global society (Bourdieu \& Passeron, 1970; Banks, 2006), groups are interacting according to their position (majority vs. minority) within the society (Smith, 2005). However, we kept in mind that, prior to adolescence, children derive their ethnic identity from others (family, peers) rather than having a feeling of belonging to an ethnic group (Phinney, 1990; Brewer, 2000; Dovidio, Kawakami, \& Gaertner, 2000). In addition, we did not explicitly plan to relate results to the developmental levels of the children who participated.

Ingroup Favoritism and Outgroup Derogation

Previous studies in the field of interracial prejudice and discrimination have indicated that intergroup biases can take two forms: ingroup favoritism and outgroup 
derogation. Ingroup favoritism refers to a tendency to favor ingroup targets via the attribution of more positive traits and the assignment of more rewards, or more responsibility for positive events, to the ingroup. In contrast, outgroup derogation refers to the tendency to devalue outgroups by allocating more negative traits, punishment, or the responsibility for negative events to them. However, the two phenomena are not reciprocally related: a positive attitude toward one's group does not necessarily represent a rejection of the outgroup (Brewer, 1999; Griffith, \& Nesdale, 2006).

Mummendey and Otten (1998) showed that ingroup favoritism occurs more frequently, because it is easier to justify socially. Comparatively, outgroup derogation is less common because subjects are more likely to refrain from expressing this kind of negative judgment (Rutland, Brown, Cameron, Ahmavaara, Arnold, \& Samson, 2007). This reflects the existence of a social norm regarding the unacceptability of expressing negative judgements (Amiot, \& Bourhis, 2003; Blanz, Mummendey, \& Otten, 1997; Mummendey, \& Otten, 1998). Social pressure may, indeed, influence people to present social desirability biases by articulating positive attitudes towards minority groups while still holding implicit negative biases. To prevent these potential social desirability biases, researchers have adopted measures capable of disentangling this bias by obtaining subjects' uncontrolled responses through the use of linguistic categorization analyses that expose implicit attitudes (Dambrun \& Guimond, 2004).

Among implicit measures, language measures, particularly the level of abstraction of predicates in spontaneous oral or written language, have received renewed attention as an effective tool for studying intergroup relations (Graumann \& Wintermantel, 1989; Hamilton, Gibbons, Stroessner, \& Sherman, 1992; Maass, Salvi, Arcuri, \& Semin, 1989; Maass, Castelli, \& Arcuri, 2000). The Linguistic Intergroup Bias (LIB) measure 
was developed mainly by Maass and colleagues (1989) on the foundation of Semin and Fiedler's linguistic category model (1988). Terms (Verbs and Adjectives) depicting behavioral episodes are divided into four linguistic categories on a continuum ranging from concrete to abstract (assigned a score of 4). Descriptive Action Verbs (DAV) are assigned to the most concrete linguistic category. They "refer to a single, observable event, by at least one physically invariant feature," such as "A picks up or punches B"; the second linguistic category contains Interpretative Action Verbs (IAV) "which are no longer bound to physically invariant features although they preserve the reference to a single behavioral episode," such as "A helps or threatens B"; the third linguistic category is defined by State Verbs (SV), describing enduring psychological and emotional states of a participant, such as "A likes or hates B"; the fourth linguistic category contains Adjectives (ADJ) which describe abstract traits such as "A is nice or mean” (Maass, et al., 1989, Table 1, p. 982). Participants have to make a choice among different assertions. Analysis concerns participants' linguistic preferences for concrete expressions (action verbs) or abstract ones (state verbs and adjectives). A score for each participant, from the most concrete to the most abstract level of linguistic preference, can then be established.

One particularly fruitful approach was adopted by Maass and colleagues in a series of experiments (Maass et al., 1989). The researchers included naturally existing groups of Italian horse racing fans who had an equal probability of placing winning bets. Members of the two groups were shown cartoons in which an ingroup or outgroup target was depicted as isolated or interacting with another protagonist, performing either socially positive behaviors (e.g., helping) or negative behaviors (e.g., littering). In a forced choice format (experiment 1), subjects were provided with four 
response options that corresponded to the different levels of abstraction in the linguistic category model. In a free-response format (experiment 2), subjects were instructed to provide a short description of scenes analogous to the ones described above. In the forced-choice condition, the authors showed that positive actions performed by an ingroup target, and negative actions performed by an outgroup target, were described in a more abstract way than positive actions by an outgroup target, or negative actions by an ingroup target. However, in the free description condition, these results were replicated only for positive actions; results failed to show negative actions performed by an outgroup target described in a more abstract way than when performed by an ingroup target. It is also interesting to note that these biases occurred for interactive, as well as non-interactive, scenarios.

\section{Effects of Group Status}

Numerous laboratory-based group studies have demonstrated convincingly that group status has an effect on favoritism and derogation, however, there are several differing patterns of reponses (Brewer \& Brown, 1998). The first response pattern is one in which assignment to high-status or powerful groups (i.e., majority groups) led people to display ingroup favoritism, specifically on dimensions that favored their own group in situations where they perceived their status as legitimate but unstable (Turner $\&$ Brown, 1978) because, in these situations, the high status group is more likely to feel insecure. In contrast, ingroup favoritism decreases when dimensions considered are irrelevant to one's status and the majority group status advantage is stable and not subject to threat (see meta-analysis conducted by Mullen, Brown \& Smith, 1992). In a second response pattern, assignment to low-status or powerless groups (i.e., minority groups) may produce outgroup favoritism (Sachdev \& Bourhis, 1991) particularly if 
inferiority is perceived as legitimate and stable (Boldry \& Kashy 1999). Outgroup favoritism has been shown among children of diverse minority groups, such as: Caribbean-Africans in England (Milne, 1975), Maoris in New-Zealand (Vaughan, 1978) or Amerindians in Canada (Corenblum \& Annis, 1993). All these results have been conceptualized within the System Justification Theory (Jost \& Banaji, 1994; Jost \& Hunyady, 2002) which describes how groups behave in specific ways to maintain the status quo of the society in which they belong, especially when this status quo is perceived as legitimate and justified. Therefore, it is expected that higher-status group members tend not to question a system that is advantageous for them. At the same time, lower-status group members tend to derogate themselves because they have internalized the existing hierarchy and accepted it, even to their disadvantage (Jost \& Banaji, 1994; Guimond, Dif, \& Aupy, 2002).

In a contrasting response pattern, in line with Tajfel and Turner's Social Identity Theory (1986), some studies have demonstrated that lower status groups may therefore be more inclined to show ingroup favoritism to establish a more favorable identity. Thus, the need for positive social identity would be the basic motivational mechanism responsible for this ingroup bias. In line with this research, it has been demonstrated that ingroup favoritism is generally more important when: (a) status differences are perceived as unstable and illegitimate by a minority group (Ellemers, Wilkes, \& Van Knippenberg, 1993); (b) it is difficult for the members of the minority group to be upwardly mobile within the majority group (Moghaddam \& Perreault, 1997); and (c) people have a strong feeling of belonging to their goup (Spears, Doosje \& Ellemers, 1997). Moreover, outgroup derogation may appear when the intergroup comparison focuses on irrelevant dimensions (Reichl, 1997; Karasawa, Karasawa \& Horose, 2004). 
LIB studies developed by Maass, Ceccarelli, and Rudin (1996) provide an interesting perspective concerning the effect of group status on linguistic productions. Using natural groups, Southern Italians (minority group) vs. Northern Italians (majority group), the authors observed that the low-status group described negative ingroup and positive outgroup behavior shifting their language toward the concrete pole, rather than the abstract pole of the continuum, whereas the high-status group did not show the LIB pattern for the outgroup. In contrast, using the Minimal Group Paradigm, Moscatelli, Albarello and Rubini (2008) did not observe a difference between high and low status group responses. Participants of high-status groups (vs. low-status groups) were asked to describe a choice (parity $v s$. ingroup favoritism $v s$. outgroup favoritism) made by either an ingroup or an outgroup member in allocating negative outcomes (i.e., seconds of noise to be transmitted through earphones). Results showed a similar degree of LIB in the high and low-status groups.

\section{Ethnic group relations in France}

There are many studies focusing on immigrant community groups in France, but few are specifically centered on Black and White intergroup relations. None include Black participants. Two main reasons may explain this situation.

First, as pointed out by Tin (2008) the Black question is always taboo in France. This is made evident by the name used to designate this group. According to Tin, the expression "Black minority" refers to men and women sharing a common social experience: that of discrimination, resulting from biases based only on skin color, not on geographic origins or religious preferences. Nevertheless, the term "Black minority" is not used consensually. Boittin (2009) noted that studies on the colonialist history of 
France show that the term "Black" is pejorative because it refers to the concept of "race" mentioned by people in metropolitan France to explain and justify their perception of asymmetric relations between "White" and "Black" people at the beginning of the twentieth century.

Second, collecting and publishing ethnic statistics is forbidden in France, and "Black" is not considered an acceptible category for data collection and analyses. Researchers who are administering questionnaires are not permitted to directly ask participants if they are "Black" or "White". Only questions about geographic origins or native language are authorized. As a matter of fact, the Freedom of Information Act (Article 8, 1978) updated in August 25, 2010, states that "it is forbidden to collect or process personal data that directly or indirectly relates to: (a) the racial or ethnic origin, political, philosophical, religious or trade union membership of individuals; or (b) characteristics that are related to individuals' state of health or their sex life. "

In order to identify Black participants, we included items on the citizenship of participants, their country of origin, and the country of origin of their parents. Through analysis of the data, we were able to identify and retain responses of children from the 48 nations that make up Sub-Saharan Africa, who were born in Sub-Saharan Africa of parents born in Sub-Saharan Africa. What is now labelled Sub-Saharan Africa (L'Afrique Sub-saharienne) by the French was once labelled Black Africa (Afrique Noire) and, obviously, is an area that is inhabited by a vast majority of people with black skin.

In this context, it is not possible to include an assessment of self-identification with ethnic group or skin color, nor to include a measurement of feelings of being discriminated against, so it is not possible to know if participants consider themselves to 
belong to the Black community ( $v s$. to a specific country) or to compare perceptions that Black and White people have of each other. This explains why most French studies are focused on perceptions that "French" people have towards different "minority" groups classified geographically. In this area of research on intergroup relations, Lambert, Moghddam, Sorin and Sorin (1990) have demonstrated that the attitude of "French" people towards Maghreb-Arab people is globally unfavorable. The attitude towards people from Sub-Saharan Africa is also negative, but it is not as strong. Finally, the attitude towards the Portuguese, Italians, and Southeast Asians, in particular, is globally favorable.

Given these limitations, the construction of the social identity of the Black Minority in France is not simple (Ndiaye, 2008). Most Black people define themselves, as French, and from an African country. Ndiaye has labelled this a "minority paradox". The Black minority seeks to be visible and invisible at the same time. On the one hand, being visible permits individuals to establish an identity in their society and to be recognized as having, for example, an Afro-Caribbean culture which contributes to the rich ethnic diversity of French society. On the other hand, being invisible allows them to manifest their desire to be integrated and bypass a sense of being discriminated against due to their skin color.

Upon review of social psychological studies on intergroup relations in France, it is evident that the majority of studies focused on intergroup relations between the French majority group and the largest geographically-defined minority group who are immigrants or their descendants from the Maghreb-Arab countries (for example, Algeria, Morocco, and Tunisia). At present, there are few studies that include participants of the Black community. For example, the study conducted by Dambrun, 
Gatto and Roche (2005) included children of French origin (majority group) and children of Maghreb origin (minority group) from 8 to 10-years-old. They used an explicit and an implicit measure. Results confirmed an ingroup favoritism bias both at the implicit and explicit levels in the majority French children only; the minority group children displayed neither ingroup attachment nor outgroup hostility at the explicit level but showed outgroup favoritism bias at the implicit level. This last result is consistent with results of the classic study by Clark and Clark (1947).

A series of studies conducted by Salès-Wuillemin and Gilibert (2004) focused on the French (majority group) community's attitudes towards the Maghreb-Arab community using linguistic measures. The participants were given a text depicting an ingroup versus an outgroup target performing a positive versus a negative action. The subject's task was to state the causes of the described situation. The authors compared explicit measures (attribution scales) and implicit measures (linguistic features). Linguistic features consisted of the target focus (i.e., the frequency with which the target was mentioned) as an indicator of an internal cause of the action. The more the target was mentioned, the more the stated cause was implicitly focused on the target, and the more the stated cause was assumed to be internal. In contrast, the less the target was mentioned, the more the stated cause was assumed to be due to environmental and situational factors and the more the stated cause of the action was considered to be external. It was observed that when focusing on a positive action, participants showed ingroup favoritism as demonstrated by a high ingroup target frequency relative to the outgroup target frequency. When focusing on a negative scenario, outgroup derogation was found. However, this was only observed with the implicit measures, as demonstrated by a higher target frequency with outgroup targets. 
The present study focused on White and Black childrens' attitudes in the French context. Participants representing both groups were included in the study. Our minority group consisted of children of Black African heritage (both the parents and the child were from a Sub-Saharan African country). Our majority group included children of White European heritage. We experimentally manipulated: (a) type of behavior (positive/negative), (b) group status (majority/minority), and (c) target membership (ingroup/outgroup). Analyses included: (a) target focus (i.e., the frequency with which the target was mentioned), and (b) LIB (i.e., use of concrete or abstract terms to describe target characteristics and actions).

We considered the inquiry of Lambert and colleagues (1990) showing that attitudes toward Black people in France are less negative than toward Maghreb-Arab people. In addition, we had in mind the two experiments conducted by Dambrun and colleagues (2005), and by Salès-Wuillemin and Gilibert (2004) about the attitudes of French people toward Maghreb-Arab people. Therefore, we hypothesized that, at the implicit level, children of the White Majority group would exhibit ingroup favoritism but no outgroup derogation bias. When confronted with an ingroup target, we expected that these participants would: (a) focus more frequently on the ingroup target when the action was positive rather than negative; (b) use more concrete terms to designate the target when the action was negative rather than positive; and (c) use more abstract terms when the action was positive rather than negative (Hypothesis 1). When the target was an outgroup member, we expected no differences between positive and negative actions in relation to the target frequency and the use of abstract terms to designate the target (Hypothesis 2). 
In the absence of studies in France concerning perceptions of Black people toward their own community, or toward White people, we did not form a hypothesis about the responses of Black participants.

\section{Method}

\section{Pilot Study 1 : Photo selection}

The photos were constructed and tested for their appropriateness prior to the study. In this first pilot study, a series of eight photographs were tested (four photos representing a target character performing a positive action (playing with a child, laughing with a child, giving a toy to a child, or comforting a crying child), and four photos representing a negative action (copying from another child, insulting another child, shoving another child, or hitting another child). The objective of this pilot study was to select the photo representing the most typical action within each of these categories based on child participants' responses.

This pilot study was conducted with 20 children, five each within the following age ranges: (7 years to less than or equal to 8 years); (greater than 8 years to less than or equal to 9 years); (greater than 9 years to less than or equal to 10 years); (greater than 10 years to less than or equal to 11 years).

Children were invited to orally select which of the four photos seemed the most representative of a positive (versus negative) action. Once this photo was designated by the child, it was set aside, and the same question was asked sequentially about the three remaining photos. This procedure allowed us to assign a rank to each photo, from rank 1 for the photo judged most typical to rank 4 for the photo judged least typical for each participant. We then calculated for each photo the number of subjects that classified it in 
rank 1 vs. another rank. A Cohen's Kappa coefficient and a $\chi^{2}$ were calculated on these data.

Results for negative actions show that a important number of participants $(\mathrm{N}=13)$ classsified the photo representing a child hitting another child at rank 1. Comparatively, the photo representing a child insulting another child was classified at rank 1 by a fewer number of participants $(\mathrm{N}=5)$, only one participant $(\mathrm{N}=1)$ ordered the photo representing a child shoving another child and the photo representing a child copying another child at rank 1 . These differences are significative $\left(\chi^{2}(3, \mathrm{~N}=20)=10.51\right.$, $\mathrm{p}=.0002$ ). More over, Cohen's Kappa coefficient shows that participants' responses are strongly inter-related (.64).

The same procedure was used concerning positive actions. Results show that a important number of participants classified the photo representing a child conforting another child $(\mathrm{N}=12)$. Comparatively, the photo representing a child giving a toy to another child was classified at rank 1 by a fewer number of participants $(\mathrm{N}=5)$. Only two participants $(\mathrm{N}=2)$ classified at rank 1 the photo representing a child playing with anonther child $(\mathrm{N}=2)$, and for the photo representing a child laughing with another child only one participant $(\mathrm{N}=1)$ dit the same; these differences are significative $\left(\chi^{2}(3, \mathrm{~N}=\right.$ $20)=10.51, p=.0002)$. More over, Cohen's Kappa coefficient shows that participants' responses are strongly inter-related (.72).

We selected the photo presenting a child who hits another child (negative action) and the photo representing a child consoling another child (positive action).

To suit the requirements of the study, the photos were standardized in terms of the style and color of clothing, facial expression, stance, and physical attractiveness of the two characters, to ensure that skin color was the only salient factor. Each picture was 
representing two characters with the same skin color. Each photo depicted an ingroup or outgroup target character performing a consoling or aggressive behavior on another character ${ }^{1}$.

Pilot study 2 : Questionnaire construction

The second pilot study was set up to test the experimental materials. This included: (a) comprehension of questions; (b) capacity to describe a photo; (c) capacity to imagine the cause of the behavior of a target person. Twenty children from the target age group were individually tested. The children were invited to complete a questionnaire presenting the four pre-tested photos in random order. Thus, the photos consisted of: (a) a Black child hitting another Black child; (b) a White child hitting another White child; (c) a Black child consoling another Black child; (d) a White child consoling another White child.

Participants were provided with a pen and paper in order to complete the task. To avoid any writing difficulties, children were assured that spelling errors would not be penalized and that the main objective was to write exactly what they were thinking about the situation. For each photo, children were given the task of stating and explaining the causes of the target character's behavior.

This pilot study permitted us to refine the measures by reformulating the questions that had been poorly understood. At the end of the questionnaire, in addition to sociodemographic questions, children were asked to rate task difficulty on a scale from 1 (not easy at all) to 10 (very easy). Children were also given an open-ended question asking them to guess the research objectives.

\footnotetext{
${ }^{1} \mathrm{We}$ recognize that this procedure was restrictive : we could have added to our findings if we tested several pictures of positive and negative behaviors. However, that would have increased either the number of subjects (already very significant in this study) or the length of the questionnaire (already rather long for pupils of this age).
} 


\section{Final Study}

\section{Participants and Design}

The sample used in the final study included 360 children in grades one through four who were $7-11$ years old (mean age $=10.36, S D=.85$ ). They attended schools located in lower-class urban areas on the outskirts of Paris. The children were divided into two groups, Black children of African heritage $(\mathrm{N}=180)$ or White children of European heritage $(\mathrm{N}=180)$ according to their origins. The research design was a 2 (group status) $x 2$ (target group) $\times 2$ (type of behavior) in the factorial design, with the last two factors manipulated within participants.

\section{Materials and Procedure}

Each participant was asked to complete a paper-and-pencil questionnaire with responses that corresponded to the four photos as described above. To limit order effects that might be caused by the order of presentation of the four photos, they were presented in one of the 16 possible counterbalanced sequences derived randomly from a balanced Latin square model.

Written parental informed consent was a prerequisite for study participation. Questionnaires were administered in the classroom by two research assistants, one with white skin color and one with black skin color.

\section{Dependent Measures}

Target frequency and language categorization scores were calculated for each participant, representing the main dependent variables. The coding operation was done by two independent coders. To evaluate inter-rater reliability, Cohen's Kappa coeficient was calculated as .851 . 
Target frequency corresponds to the frequency with which the main character is mentioned. This indicator is calculated by dividing target citation frequency by the number of clauses. A high frequency is interpreted as an attribution of an internal causality for a given action (Salès-Wuillemin \& Gilibert, 2004). LIB categorization scores correspond to the two meta-categories used by Maass et al. (1989) : concrete terms (Descriptive Action Verbs, like "kiss" "look" and "run" \& Interpretive Action Verbs, like "help" “offend" "inhibit") and abstract terms (State Verbs, like "believe" "love" "admire" \& Adjectives, like "honest" "helpful” "impulsive"). They are calculated by dividing the frequency with which a category is cited by the total number of clauses cited.

\section{Results}

The task was not judged by the participants as being too difficult $(M=7.4, S D=$ 1.8 on a scale of 1 to 10 , with $10=$ very easy to perform); moreover, participants were not able to guess the true purpose of the experiment.

The general MANOVA analysis showed a main effect of the type of behavior ( $F$ $(1,318)=26.60, p<.0001)$, an effect of the target group membership $(F(1,318)=5.51$, $p<.02)$. In addition, the analysis revealed a significant interaction effect between the group status and the target group membership variables $(F(1,318)=6.08, p<.02)$ and between the type of behavior and the target group membership variables $(F(1,318)=$ $6.51, p<.02)$.

In order to test specific effects for each group status on each measure, ANOVA analyses were performed with a 2 (target group membership) x 2 (type of behavior) design.

Ingroup Favoritism 
We expected ingroup favoritism for the majority group (hypothesis 1).

Insert figures 1 and 2 about here

Figures 1 and 2 depict the existence of ingroup favoritism in the majority group: thus, hypothesis 1 was confirmed. Results also reveal an ingroup favoritism in the minority group.

Both participants from the majority and the minority groups demonstrated higher target frequency for the ingroup targets when a positive action (conforting behavior) was being performed as opposed to a negative one (hitting behavior). This effect was significant for majority group participants $(M=.93, S D=.17$ and $M=.79, S D=.29)$ for positive and negative actions respectively, $\left.F(1,159)=30.33, p<.001, \eta^{2}=0.16\right)$ and for minority group participants $(M=.91, S D=.22$ and $M=.77, S D=.32, F(1,159)=20.02, p$ $\left.<.001, \eta^{2}=0.11\right)$.

Likewise, participants from the two groups used more concrete terms when the action was negative rather than positive. This effect was significant for majority group participants $\left(M=.38, S D=.16\right.$ and $M=.27, S D=.17, F(1,159)=32.42, p<.001, \eta^{2}=$ $0.17)$ and for minority group participants $(M=.39, \mathrm{SD}=.17$ and $M=.25, S D=.13$, $\left.F(1,159)=64.67, p<.001, \eta^{2}=0.29\right)$.

Finally, participants from the two groups used more abstract terms when the action was positive rather than negative. This effect was significant for the majority group participants $(M=.19, S D=0,11$ and $M=.09, S D=.05, F(1,159)=23.65, p<$ $\left..001, \eta^{2}=0.13\right)$ and minority group participants $(M=.15, S D=.09$ and $M=.06, S D=$ $\left..03, F(1,159)=37.10, p<.001, \eta^{2}=0.19\right)$. 


\section{Outgroup Derogation / Outgroup Favoritism}

We expected no outgroup derogation for the majority (hypothesis 2).

Insert figures 3 and 4 about here

Figure 3 depicts the absence of outgroup derogation in the majority group: thus, hypothesis 2 was confirmed. Participants did not demonstrate significantly higher target frequency when focusing on outgroup targets performing a negative action $(M=.89, S D$ $=.19)$ as opposed to a positive one $(M=.89, S D=.25), F<1$. They did not use more concrete terms when the action was negative $(M=.31, S D=.12)$, rather than positive $(M$ $=.34, S D=.11) F<1$. Finally, the participants did not use more abstract terms when the action was negative $(M=.10, S D=.03)$ rather than positive $(M=.12, S D=.06), F<1$.

Figure 4 shows the same pattern of results for the participants from the minority group. Like the majority group, they did not focus significantly more on the outgroup target when there was a negative action $(M=.89, S D=.20)$ as opposed to a positive one $(M=.89, S D=.24), F<1$. They did not use more concrete terms when the action was negative $(M=.30, S D=.07)$, rather than positive $(M=.33, S D=.10) F<1$. Finally, participants did not use more abstract terms when the action was negative $(M=.11, S D$ $=.13)$ rather than positive $(M=.13, S D=.11), F<1$.

\section{Discussion}

In line with recent studies of linguistic intergroup bias or linguistic target frequency, the main goal of the present study was to explore the linguistic intergroup bias between Black and White children in France. We expected ingroup favoritism and no outgroup derogation in the majority group. Our results confirmed these two 
hypotheses. Confronted with an ingroup target, the majority group demonstrated higher target frequency (i.e., mentioned the target more frequently) and described an action in more abstract terms when the action was positive rather than negative. These participants did not demonstrate significantly higher target frequency when focusing on outgroup targets performing a negative action compared to a positive one. In the same manner, they used no more concrete terms when the action was a positive one compared to a negative one and they did not use more abstract terms when the action was negative rather than positive.

Considering the presence of an ingroup favoritism and the absence of an outgroup favoritism among the majority group participants, we would suggest that the majority group participants perceived their status as legitimate and did not feel threatened by the minority group (Sachdev \& Bourhis, 1991).

Our analyses show another interesting result. Responses were similar in the majority group and in the minority one. The minority group showed ingroup favoritism with no outgroup favoritism. Taking into account the research of Ellemers and colleagues (1993) or Boldry and Kashy (1999) with our results, we can formulate a first possibility: minority group members perceive status differentials as unstable or illegitimate. However, the similarity of responses between the majority and minority groups leads us to a second possibility: if a minority group acts like the majority, then this group may feel in a majority position. We advance this assumption in relation to the experimental context. A characteristic of our research is that it was conducted in schools with multiracial populations. As a result, children of Black African heritage formed a fairly large proportion of the school population as a whole (varying from $26 \%$ to $32 \%$ within different schools). Given this context, it is possible that the Black children did 
not regard themselves as part of a minority group, instead, they considered themselves to be a part of the majority group; consequently, this minority group did not feel discriminated against. This is an interesting result. It opens promising possibilities in terms of the integration of people of diverse origins in French schools. It seems to demonstrate that in an elementary school context with a large proportion of varied minority groups, intergroup attitudes are more balanced and lead to fewer prejudicial attitudes and less discrimination aimed at visible minorities. Unfortunately, due to French legal limitations, we could not include a measurement of perceptions of being discriminated against due to skin colour, so it is not possible to confirm this explanation.

Another variable of interest could be useful in clarifying these results: the perception of discrimination felt by participants broken down by age group. Indeed, results obtained by Clark, Hocevar and Dembo (1980) demonstrated that, for children, the sense of identification with an ethnic origin or skin color as a criterion for categorization requires cognitive capacities that are acquired later in childhood, possibly as late as 10 years of age. This leads us to point out another limitation of our study: in order to have sufficient size to statistically compare groups, all of the participants' data were grouped together without distinguishing between the results of the youngest and oldest participants in the sample who ranged from seven to eleven years old.

\section{Conclusions}

Our findings highlight the utility of the use of linguistic measures for identifying implicit biases in young school children. First, they are appropriate measures to use in an applied setting because of their unobtrusive and "every-day" properties that allow children to use language spontaneously and naturally. Thus, we obtained valuable data 
derived from spontaneous responses that were not consciously controlled by the participants. Second, the use of spontaneous language by children provided an opportunity to assess both forms of ingroup bias independently, thus uncovering subtle variations in the expression of ingroup bias. Third, because language is inherently social, linguistic analyses can provide explanations of how existing stereotypes emerge and maintain themselves. As stated by Maass and colleagues (1989), “one can easily envisage a self-perpetuating cycle in which biased language use maintains, or even aggravates, initial intergroup biases in applied settings.” (p. 990). Given this perspective, studying discrimination in its inconspicuous linguistic manifestations may open fruitful new research directions.

Our research follows the line of research pursued since 1989 by Maass and her collaborators. In addition, our investigation is based on insights from a wide range of studies (Salès-Wuillemin \& Gilibert, 2004) that have adopted other language-based measures, such as target frequency. This final indicator permits us to measure internal causation, like the abstract terms coded in the LIB. The difference between these two indicators is that target frequency does not depend on semantic traits. It consists of counting the number of times the target character is mentioned. This coding presents less risk of error and the inter-rater reliability is improved.

Considering the limitations of our research mentioned above, in future research, we will complete data collection by increasing the number of subjects in each age group while tracking classroom and school-level characteristics (i.e., ethnic densities of both classrooms and schools). This future inclusion of differentiated sociodemographic characteristics is essential in order to gain a broader understanding of multicultural intergroup relations in the French elementary school context. Given this objective, we 
will also undertake a qualitative study including anonymous individual interviews with children from African heritage to gain a more wholistic perspective of their attitudes and behaviors related to intergroup relations. We will select a school and four classes in which we will test all children. The interviews will focus on violence and antisocial behavior at school. We will only consider the responses of children born in Sub-Saharan Africa.

Consistent with the research of Berry and Sabatier (2010) it will then be possible to measure reactions to discrimination and acculturation strategies in terms of assimilation, integration, marginalisation and separation (AIMS). Another development of this research, consistent with Maoz (2000) may take the form of focus group interviews with both groups. It will then be possible to analyze processes and patterns of power relations between majority and minority groups using language and conversational analysis methodology (Minondo \& Salès-Wuillemin, 2005). 


\section{References}

Amiot, C., \& Bourhis, R. Y. (2003). Discrimination and the positive-negative asymmetry effect: Ideological and normative processes. Personality and Social Psychology Bulletin, 29, 597-608.

Banks, J. A. (2006). Improving race relations in schools: From theory and research to practice. Journal of Social Issues, 62(3), 607-614.

Berry, J., \& Sabatier, C. (2010). Acculturation, discrimination, and adaptation among second generation immigrant youth in Montreal and Paris, International Journal of Intercultural Relations, 34(3), 191-207.

Blanz, M., Mummendey, A., \& Otten, S. (1997). Normative evaluations and frequency expectations regarding positive versus negative outcome allocations between groups. European Journal of Social Psychology, 27, 165-176.

Boldry J. G., \& Kashy, D. A. (1999). Intergroup perception in naturally occurring groups of differential status: A social relations perspective. Journal of Personality and Social Psychology, 77, 1200-1212.

Boittin, J. (2009). Black in France: The language and politics of race in the late third republic. French Politics, Culture \& Society, 27(2) 23-46.

Brewer, M. B. (1999). The psychology of prejudice: Ingroup love or outgroup hate? Journal of Social Issues, 55(3), 429-444.

Brewer, M.B. (2000). Reducing prejudice through cross-categorization: Effects of multiple social identities. In S. Oskamp (Ed.) Reducing prejudice and discrimination (pp. 165-183). Mahwah, NJ: Lawrence Erlbaum. 
Brewer, M. B., \& Brown, R. J. (1998). Intergroup relations. In D. T. Gilbert, S. T. Fiske, \& G. Lindzey, (Eds.), The Handbook of Social Psychology (pp. 554-594), Vols. 1 and 2 (4th ed.). New York: McGraw-Hill.

Bourdieu, P., \& Passeron, J.C. (1970). La reproduction. Paris: Editions de Minuit.

Clark, K. B., \& Clark, M. P. (1947). Racial identification and preference in Negro children. In T. M. Newcomb, \& E. L. Hartley (Eds.), Readings in Social Psychology (pp.169-178). New York: Henry Holt and Company.

Clark, A., Hocevar, D., \& Dembo, M. H. (1980). The role of cognitive development in children's explanations and preferences on skin color. Developmental Psychology, 16(4), 332-339.

Corenblum, B., \& Annis, R. C. (1993). Development of racial identity in minority and majority children: An affect discrepancy model. Canadian Journal of Behavioral Sciences, 25, 499-521.

Dambrun, M., Gatto, J., \& Roche, C. (2005). L'effet du statut du groupe d'appartenance sur les attitudes ethniques implicites et explicites chez les enfants. Cahiers Internationaux de Psychologie Sociale, 67/68(3-4), 65-76.

Dambrun, M., \& Guimond, S. (2004). Implicit and explicit measures of prejudices and stereotypes: Do they assess the same underlying knowledge structure? European Journal of Social Psychology, 34, 663-676.

Dovidio, J. F., Kawakami, K., \& Gaertner, S. L. (2000). Reducing contemporary prejudice: Combating explicit and implicit bias at the individual and intergroup level. In S. Oskamp (Ed.), Reducing prejudice and discrimination (pp. 137-163). Mahwah, NJ: Lawrence Erlbaum. 
Eberhard, M., \& Simon, P. (2012). Synthèse, égalité professionnelle et perception des discriminations, Enquête auprès d'agents de la ville de Paris [monograph]., INED, retrieved from:

http://www.ined.fr/fichier/t_presse_fichier/59/fichier_fichier_fr_synth.se.simon.m airieparisdef.pdf

Ellemers, N., Wilke, H., \& Van Knippenberg, A. (1993). Effects of the legitimacy of low group or individual status on individual and collective identity enhancement strategies. Journal of Personality and Social Psychology, 64, 766-78.

Graumann, C. F., \& Wintermantel, M. (1989). Discriminatory speech acts. In D. BarTal, C. F. Graumann, A. W. Kruglanski, \& W. Stroebe (Eds.), Stereotyping and prejudice: Changing conceptions (pp. 183-204). New York: Springer-Verlag.

Griffiths, J. A., \& Nesdale, D. (2006). Ingroup and outgroup attitudes of ethnic majority and minority children. International Journal of Intercultural Relations, $30,735-749$.

Guimond, S., Dif, S., \& Aupy, I. (2002). Social identity, relative group status and intergroup attitudes: When favourable outcomes change intergroup relations ... for the worse. European Journal of Social Psychology, 32, 739-760.

Hamilton, D. L., Gibbons, P. A., Stroessner, S. J., \& Sherman, J. W. (1992).

Stereotypes and language use. In G. R. Semin, \& K. Fiedler (Eds.), Language, interaction and social cognition (pp. 102-128). London: Sage.

Jost, J. T., \& Banaji, M. R. (1994). The role of stereotyping in system-justification and the production of false consciousness. British Journal of Social Psychology, 33, $1-27$. 
Jost, J. T., \& Hunyady, O. (2002). The psychology of system justification and the palliative function of ideology. In W. Stroebe, \& M. Hewstone (Eds.), European Review of Social Psychology, 13(1), 111-153.

Karasawa, M., Karasawa, K., \& Hirose,Y. (2004). Homogeneity perception as a reaction to identity threat: Effects of status difference in a simulated society game. European Journal of Social Psychology, 34, 613-625.

Lambert, W. E., Moghaddam, F. M., Sorin, J., \& Sorin, S. (1990). Assimilation vs multiculturalism: View from a community in France, Sociological Forum, 5(3) $387-411$.

Maass, A., Salvi, D., Arcuri, L., \& Semin, G. (1989). Language use in inter-group contexts: The linguistic inter-group bias. Journal of Personality and Social Psychology, 57, 981-993.

Maass, A., Ceccarelli, R., \& Rudin, S. (1996). Linguistic intergroup bias: Evidence for ingroup-protective motivation. Journal of Personality and Social Psychology, 71(3), 512-526.

Maass, A., Castelli, L., \& Arcuri, L. (2000). Measuring prejudice: Implicit versus explicit techniques. In D. Capozza, \& R. Brown (Eds.), Social Identity Processes (pp. 96-116). London: Sage.

Maoz, I. (2000). Power relations intergroup encounters: A case study of Jewish-Arab encounters in Israel. International Journal of Intercultural Relations, 24(2), 259277.

Milner, D. (1975). Children and Race. Harmondsworth : Penguin.

Minondo, B., \& Salès-Wuillemin, E. (2005). Les communications fonctionnelles experts/novices: Effet de la mise en saillance catégorielle sur le pilotage du 
dialogue et la relation instaurée avec le partenaire, Bulletin de Psychologie, 58 (477), 329-338.

Moghaddam, F. M., \& Perreault, S. (1997). Individual and collective mobility strategies among minority group members. Journal of Social Psychology, 132(3), 342-357.

Moscatelli, S., Albarello, F., \& Rubini, M. (2008). Linguistic discrimination in minimal groups: The impact of status differentials. Journal of Language and Social Psychology, 27, 140-154.

Mullen, B., Brown, R., \& Smith, C. (1992). Ingroup Bias as a function of salience, relevance and status: An integration. European Journal of Social Psychology, 22, 103-122.

Mummendey, A., \& Otten, S. (1998). Positive-negative asymmetry in social discrimination. European Review of Social Psychology, 9, 107-143.

Ndiaye, P. (2008). La condition Noire, essai sur une minorité française. Paris : Calmann Levy.

Phinney, J. S. (1990). Ethnic identity in adolescents and adults: A review of research. Psychological Bulletin, 108, 499-514.

Rutland, A., Brown, R. J., Cameron, L., Ahmavaara, A., Arnold, K., \& Samson, J. (2007). Development of the positive-negative asymmetry effect: Ingroup exclusion norm as a mediator of children's evaluations on negative attributes. European Journal of Social Psychology, 37, 171-190.

Sachdev, I., \& Bourhis, R. Y. (1991). Power and status differentials in minority and majority group relations. European Journal of Social Psychology, 21, 1-24. 
Salès-Wuillemin, E., \& Gilibert, D. (2004). Les indicateurs discursifs de l'explication. In M. Bromberg, \& A. Trognon (Eds.), Psychologie Sociale et Communication, (pp. 229-244). Paris: Dunod.

Semin, G. R., \& Fiedler, K. (1988). The cognitive functions of linguistic categories in describing persons: Social cognition and language. Journal of Personality and Social Psychology, 54, 558-568.

Smith, R.A. (2005). The classroom as a social psychology laboratory. Journal of Social and Clinical Psychology, 24(1), 62-71.

Snyders, G. (1976). Ecole, classe et lutte des classes. Paris: Presses Universitaires de France.

Spears, R., Doosje, B., \& Ellemers, N. (1997). Self-stereotyping in the face of threats to group status and distinctiveness: The role of group identification. Personality and Social Psychology Bulletin, 23(5), 538-553.

Tajfel, H., \& Turner, J. C. (1986). An integrative theory of intergroup conflict. In S. Worchel, \& W. G. Austin (Eds.), The psychology of intergroup relations (pp.724). New York: Nelson-Hall.

Tin, L. G. (2008). Who is afraid of Black in France? The Black question: The name taboo, the number taboo. French Politics, Culture and Society, 26(1), 32-44.

Turner. J. C., \& Brown, R. (1978). Social status, cognitive alternatives, and intergroup relations. In H. Tajfel (Ed.), Differentiation between social groups: Studies in the social psychology of intergroup relations (pp. 202-234). New York: Academic Press.

Vaughan, G. M. (1978). Social change and intergroup preferences in New Zealand. European Journal of Social Psychology, 8, 297-314. 
Zick, A., Pettigrew, T.F., \& Wagner, U. (2008). Ethnic prejudice and discrimination in Europe, Journal of Social Issues, 64(2), 233-251. 